\title{
Factors Influencing the Timing of First Sexual Intercourse Among Young People in Nyanza, Kenya
}

\begin{abstract}
CONTEXT: Despite the relevance of the timing of first intercourse for the risk of HIV infection, few studies have examined postponement of first sex as a strategy to prevent infection.
\end{abstract}

METHODS: Survey data collected in October 2003 from 8,183 standard six and standard seven students aged 11-17 in 160 schools in Nyanza Province, Kenya, were used in logit and log-normal hazard models to understand the factors that influence the timing of first sexual intercourse.

RESULTS: Both males and females who rejected myths about HIV transmission, those who experienced less sexual pressure and those who did not know anyone who had died of AIDS, as well as males who had a stronger belief in their ability to abstain, were more likely to postpone sexual intercourse than were young people who lacked those characteristics. Although lower levels of perceived HIV risk were associated with early sexual initiation, adolescents who felt they were at no risk of HIV infection were most likely to postpone initiation. The pattern of associations across gender suggests that males are pressured into very early sexual activity to prove their maturity, although males who had confidence that they could abstain were more likely to do so. Females, however, were not able to translate belief in their ability to abstain into abstinence and were influenced to engage in intercourse by social and environmental pressures.

CONCLUSIONS: To support delays in sexual initiation, HIV prevention programming and policy need to be focused on dispelling myths about HIV transmission and countering the gendered pressures that young people feel to initiate sexual activity during their early adolescence.

International Family Planning Perspectives, 2008, 34(4):177-188

\section{By Eric Yeboah \\ Tenkorang \\ and Eleanor \\ Maticka-Tyndale}

Eric Yeboah

Tenkorang is postdoctoral research

fellow, and

Eleanor Maticka-

Tyndale is professor,

Department of Sociol-

ogy and Anthropology, University of Windsor,

Ontario, Canada.
Initiation of sexual intercourse at an early age contributes to vulnerability to HIV infection by exposing adolescents to more sexual partners and a longer period of sexual activity before they form long-term monogamous relationships. ${ }^{1-4}$ Studies in Nigeria, ${ }^{5}$ Kenya, ${ }^{6}$ Tanzania, ${ }^{7}$ Uganda ${ }^{8}$ and South Africa ${ }^{9}$ all suggest that early initiators are less likely to know how to prevent STIs, including HIV, or to be able to negotiate condom use than are those who delay sexual intercourse. For young females, early initiation poses additional risks because of their physiological immaturity and the power differentials between them and older male partners. ${ }^{10-15}$

Luke $^{15}$ and others ${ }^{16-19}$ have argued that the socioeconomic environment that prevails in most Sub-Saharan countries encourages early sexual activity, especially among females. Young females' tendency to give in to the sexual pressures of older males is influenced by their youth and inexperience, their socialization to acquiesce to male authority and their potential economic dependence on male partners. ${ }^{6,13}$ In Kenya, in qualitative interviews with upper primary school youth, both females and males spoke of financial pressures and motivations to engage in sex with older partners, contributing to both sugar mommy and sugar daddy relationships. 12,16,17,20,21

Although these factors may motivate youth to engage in sexual activity, several models have theorized that the per- ceptions that AIDS is serious and that one is at risk of acquiring HIV can motivate individuals to adopt such riskreducing behaviors as delaying sexual debut, avoiding sexual activity or using condoms. ${ }^{22-25}$ Evidence supporting these theories has been found in several South African studies $^{26-28}$ in which delayed sexual debut was associated with having known someone who had died of AIDS and perceiving one's own risk of becoming infected as high.

Despite the importance of postponement of first intercourse for AIDS risk reduction, few studies have examined postponement as a preventive strategy. The current study, based on the Information-Motivation-Behavioral Skills (IMB) framework, ${ }^{29}$ was designed to identify factors associated with postponement of first sexual intercourse among upper primary school students in Nyanza Province, Kenya. The IMB model has proven effective in predicting HIV risk and risk-reducing behaviors, ${ }^{29-32}$ and has been used to design successful prevention programs. ${ }^{30,33,34}$ The model specifies that a person engaging in a particular self-protective behavior (such as postponing sexual intercourse) is influenced by knowledge that the behavior reduces the risk of infection. To engage in the behavior, the person must be motivated to do so and have the requisite self-efficacy and skills.

Our analyses use data collected in October 2003 as part of the annual monitoring and evaluation of an HIV education program conducted in 2001-2006. ${ }^{35}$ 


\section{BACKGROUND}

A 1997 World Health Organization (WHO) multicity study found that more than 20\% of 15-19-year-old women in Kisumu, the capital city of Nyanza, and nearly $40 \%$ of 20-24-year-old women were infected with HIV, compared with fewer than $5 \%$ and slightly more than $10 \%$, respectively, of men in those age-groups. ${ }^{36}$ In 2000, Nyanza Province, which borders Lake Victoria in southwestern Kenya, had an HIV prevalence of 22\%-the highest of any province in the country. ${ }^{37}$ These findings led the Kenyan Ministry of Education to identify Nyanza Province as a high priority region for HIV prevention programming.

One such effort was the Primary School Action for Better Health program. To inform development of the program, surveys, interviews and focus groups were conducted in primary schools and their surrounding communities in 2001. This preliminary research showed high rates of early sexual activity among upper primary school pupils* and identified multiple factors that youth and adults alike claimed were pushing or forcing youth to be sexually active. ${ }^{16,17}$

In keeping with the IMB framework of HIV prevention, the program aimed to counter these factors by delivering accurate information about HIV transmission and prevention (including information on the role of condoms in reducing risk). The program conveyed both general knowledge about HIV and specific facts that debunked local myths about HIV transmission and prevention. Such myths, which portray HIV as being transmitted supernaturally or through mundane daily contacts and activities, may lead people to view HIV as nearly impossible to avoid. This fatalistic outlook hampers prevention efforts, particularly if prevention requires individuals to behave contrary to local customs. ${ }^{17,38}$

The program was also designed to enhance the motivation, behavioral self-efficacy and skills of youth to delay or reduce sexual activity ${ }^{35}$ by raising awareness about the seriousness of AIDS and the personal risk for those who were sexually active. In addition, the participants were taught strategies for avoiding or dealing with pressures to be sexually active and building their confidence in their ability to postpone sexual activity. ${ }^{\dagger}$ A formal evaluation of the program demonstrated gains in modifying sexual behaviors, knowledge and self-efficacy. ${ }^{39}$ The question addressed in this article is whether information, motivation and behavioral self-efficacy significantly affect the timing of first sexual intercourse.

\section{METHODS}

\section{Ethical Considerations}

The research protocol was reviewed by the office of the Provincial Director of Education for Nyanza Province and by the Research Ethics Board of the University of Windsor,

* $34 \%$ of 12 -year-olds, $53 \%$ of 15 -year-olds and $68 \%$ of 17 -year-olds reported that they had already engaged in sexual intercourse; there were no statistically significant differences between males and females.

†All training and curriculum materials are available on the project Web site, $<$ http://www.psabh.info $>$, or from the Kenyan Ministry of Education.
Ontario, Canada. Given the number of orphans and children not under the regular care of parents in the schools and the considerable stigmatization of families affected by HIV, we were advised by school and community representatives that the process of individually obtaining parental consent could discourage the participation of children affected by HIV and would also contribute to their identification and stigmatization. As a result, following a community meeting at which the HIV prevention program and the research to be conducted were presented, schools, in consultation with their local school committees (including parents), exercised their authority to grant the research team access to the pupils and to permit pupils to make their own decisions about research participation. ${ }^{40}$

\section{Sample and Data Collection}

All standard six and seven pupils (equivalent to grades six and seven in North America) at school on the data collection day were given the opportunity to participate in the survey. An information sheet was provided for each pupil in both English and the most commonly used local language and was read aloud to groups of pupils by the trained, multilingual team of Kenyan research assistants who later administered the survey. Pupils were informed that they could refuse to participate in the research or decline to answer specific questions, and that completing the questionnaire would be taken as their agreement to participate.

In October 2003, surveys were completed by 8,183 standard six and seven pupils in the 160 schools selected through stratified random sampling of schools in districts that were participating in the program. Surveys were read aloud in English and the local language as pupils, separated into same-sex classrooms, followed along on their own copies of the surveys (written in both languages) and marked their answers.

\section{Questionnaire Development}

The questionnaire was based on the HIV/AIDS Prevention Monitoring and Evaluation Kit, ${ }^{41}$ developed by WHO and the United Nations Educational, Scientific and Cultural Organization (UNESCO), as well as elicitation research that used focus groups of standard six and seven pupils to develop measures appropriate to the local context. Pretesting of the research process and questionnaire was conducted in 24 schools; 1,021 pupils completed questionnaires and six focus groups were conducted during the 2000 school year. Questions were tested for clarity, pupil comprehension and internal validity. Scales were tested for internal and construct validity.

\section{Measures}

Two dependent variables were used in the analyses presented here: whether students had ever played sex (the local term for penile-vaginal penetration) and the age at which they first did so. The latter variable was right censored for those who had not yet experienced their sexual 
debut.* The primary independent variables were knowledge about ways to avoid HIV infection, endorsement or rejection of myths about HIV transmission, experience of pressures to engage in sexual intercourse, perception of one's own risk of contracting HIV, personally knowing someone who had died of AIDS, abstinence self-efficacy and condom use self-efficacy. In addition, ethnic group and religion were included as controls.

Knowledge about HIV prevention was measured with two multidimensional scales created for this project from responses to 12 questions ( six factual statements from the WHO/UNESCO kit and six local myths identified in preliminary research) about how infection with HIV may be avoided. The factor analysis option in LISREL, ${ }^{\dagger}$ used to develop all scalar measures, identified two latent constructs that we called prevention knowledge and transmission myths. The six factual prevention statements (HIV/AIDS can be prevented by avoiding sex, having fewer sexual partners, not sharing razor blades, being faithful to an uninfected partner, using condoms and making sure injections are done with clean needles) loaded heavily on prevention knowledge. The six myths about transmission (HIV can be transmitted through wearing the clothes of someone sick with AIDS, by sharing plates of food with an infected person, by mosquitoes and other insects, by having sex with thin people or shaking hands with someone sick with AIDS, and can be avoided by eating a good diet) loaded heavily on transmission myths. Correct responses were coded as 1 and incorrect ones were coded as 0 . Scalar measures of each form of knowledge were created by summing responses weighted by their respective factor scores. Reliability coefficients (Cronbach's alpha) ${ }^{\ddagger}$ were 0.82 and 0.78 for prevention knowledge and transmission myths, respectively. High positive values on prevention knowledge indicate correct knowledge about AIDS prevention, while negative values indicate an absence of such knowledge. In contrast, high positive values on transmission myths indicate endorsement of myths that convey false information about transmission and prevention of HIV, while negative values indicate rejection of these myths.

Motivations related to first sexual intercourse were measured both in terms of the pressures pushing respondents toward early initiation, as well as the personal motivations helping them delay initiation. The former were measured with a scale that was made up of indicators developed from what young people reported in the elicitation focus groups as experiences that motivated them to engage in sexual intercourse. ${ }^{16,17}$ On the survey, students were asked whether they had ever felt pressured to engage in sexual intercourse because their own bodies pushed them to have sex, their friends encouraged them, an older person encouraged them, their boyfriend or girlfriend wanted to have sex, they would receive money or gifts, someone had arranged for them to have sex, they did not know how to resist their partner, they had watched someone else have sex, or someone had tried to physically force them to have sex. The instructions accompanying these questions clarified that responding to items in the affirmative did not necessarily mean that they had engaged in intercourse, but merely that they had experienced the pressure. Affirmative responses were coded as 1 and negative responses as -1 . All indicators loaded on a single latent construct, with factor loadings ranging from 0.49 to 0.69 and a Cronbach's alpha of 0.75 . A scale that we called sexual pressure was created by summing the items, which were weighted by their factor scores. Higher positive values on the scale indicated experiencing a larger number of pressures to engage in sexual intercourse, while lower values indicated experiencing fewer pressures.

Two motivators to avoid sexual intercourse included perceiving oneself as being at risk and perceiving AIDS as serious. Risk perception was measured as an ordinal variable with four categories that were dummy coded; no risk was the reference category, compared with responses of small, moderate or great risk. Following examples set in research in South Africa, ${ }^{26-28}$ we measured participants' perception of the seriousness of AIDS by their reports of whether they personally knew someone who had died of AIDS, with "yes" and "don't know" dummy coded against the reference category, "no."

Behavioral self-efficacy was measured using scale scores on abstinence and condom use self-efficacy. The scales comprised the weighted sum of responses to questions that asked respondents if they believed that they could say no to sex; that when a girl says no to sex, she really means it; that they would be able to have a boyfriend or girlfriend for a long time without engaging in sexual intercourse; that they could tell their boyfriend or girlfriend that they (the couple) would abstain from sexual intercourse until marriage; that they could tell their boyfriend or girlfriend about condoms; and that they could insist on condom use during sexual intercourse. Responses on a five-point ordinal Likert scale ranged from "definitely yes" (5) to "definitely no" (1). The first four indicators loaded on a latent construct that we called abstinence self-efficacy, while the last two loaded on condom use self-efficacy.

Religion and ethnicity were measured by personal identification as Catholic, Protestant or other and as belonging to one of the two dominant ethnic groups in the region, the Luo and the Kisii; smaller ethnic groups were collapsed into "other." These variables were also dummy coded, with Catholic and Luo as the reference categories.

*This is a standard technique in analyses of this type to minimize loss of data.Zaba et al. ${ }^{52}$ recommend retaining the right-censored data and using survival analysis with data such as these.

HLISREL produces and uses polychoric and polyserial correlations ( $R$ squares) with categorical and ordinal variables because they provide more accurate results with such variables.

fLISREL uses asymptotic covariance matrices that provide R-squares for each indicator. These show how reliable each indicator is for the latent variable. Cronbach's alpha is limited in this case because it is meant for interval- or ratio-level variables; we have provided Cronbach's alpha here since it is a familiar and commonly used measure of internal reliability. Covariance or correlation matrices and tables reporting factor loadings for all scalar measures are available on request from the authors. 
TABLE 1. Selected characteristics of students participating in Primary School Action for Better Health, by gender, Nyanza, Kenya, 2003

\begin{tabular}{lll} 
Group and characteristic & Males & Females \\
\hline ALL & $\mathrm{N}=4,146$ & $\mathrm{~N}=4,037$ \\
Ever had sex & 61.5 & 29.9 \\
Yes & 38.5 & 70.1 \\
No & & \\
$\quad$ Informationt & & \\
$\begin{array}{l}\text { Mean prevention knowledge } \\
\quad \text { score (range,-2.09 to 0.94) }\end{array}$ & 0.01 & -0.01 \\
$\begin{array}{l}\text { Mean endorsement of transmission } \\
\quad \text { myths score (range, }-1.08 \text { to 1.60) }\end{array}$ & 0.01 & -0.01
\end{tabular}

\section{Motivation}

Mean sexual pressure score $\dagger$

$\begin{array}{lll}\text { (range, }-0.87 \text { to } 2.56 \text { ) } & 0.13 & -0.13\end{array}$

Perceived risk

None

Small

Moderate

Great

Knew someone who had died of AIDS

Yes

No

Don't know

\section{Behavioral self-efficacy}

Mean abstinence score

(range, -1.73 to 1.77 )

Mean condom use score

(range, -2.00 to 1.11 )

Demographic

Religion

Catholic

Protestant

Other

Ethnicity

Luo

Kisii

Other

Mean age of respondents

(range, 11-17)

RESPONDENTS WHO HAD HAD SEX
Age at first sex
$\leq 11$
12
13
14
15
16
17

Age difference with first sexual partner (yrs.)

$\leq 1$

$>1$ but $\leq 2$

$>2$ but $\leq 3$

$>3$

Source of partner‡

School

Family

Village

\section{Nature of first intercourse}

Wanted by respondent

Forced on respondent

86.1

9.1

9.1
1.2

3.6

\section{1}

15.1

17.2

22.1

17.3

9.5

4.7

†Scale scores were calculated as sums of questionnaire items weighted by their factor loadings. $¥$ Percentages do not total 100.0 because respondents could provide more than one answer. Note: Figures are percentages unless otherwise noted.

\section{Data Analysis}

Correlation and covariance matrices for the 11 independent variables (including gender) were produced using LISREL. Correlations are presented as absolute values $(|\mathrm{x}|)$ because they may be positive or negative. Most correlations were $|0.1|$ or lower. The two highest correlations $(|0.3|)$ were between abstinence self-efficacy and condom use self-efficacy and between factual knowledge and myths. In both cases, these correlations were between scales created from the same indicators differentiated by factor scores. Three correlations were $|0.2|$, between gender and risk perception (females perceive they are at less risk than males), ethnicity and condom use self-efficacy (Luos have higher self-efficacy than other ethnic groups), and transmission myths and abstinence self-efficacy (those who endorse more myths have higher abstinence self-efficacy). The generally low values of correlations indicated that there is little shared variance among the independent variables.

We used binary logit models to analyze the categorical dependent variable "ever had sex" and hazard models for "age at first intercourse." We employed a parametric model that allowed us not only to make inferences about the timing of the event of interest, but also to simultaneously examine the independent effects of the selected covariates on the timing of first sexual intercourse. We used a lognormal rather than log-logistic regression model because it was a better fit for the underlying distribution of the dependent variable and produced both higher log-likelihood ratios for nested models and lower AIC* statistics for nonnested models. The dependent variable of how early or late an individual first engaged in sexual intercourse was measured with time ratios. A time ratio of less than one indicated first sexual intercourse at an earlier age than the comparison group and a ratio greater than one, first intercourse at a later age than the comparison group (Figure 1). For ease of interpretation, time ratios can be converted to percentages that reflect how much earlier or later an event occurs. This is interpreted along the same lines as unstandardized coefficients in an ordinary least squares regression (i.e., how much earlier or later something occurs for each unit increase in the independent variable). In our bivariate analysis, the percentage reflects how much earlier or later (the percentage of time) an individual first experiences sexual intercourse for each one unit increase in the independent variable of interest for continuous variables and the increase between those coded 0 and 1 in dummycoded variables. In multivariate analysis, this is the change for an individual who is at the mean value (or coded 0 for dichotomous variables) for all other independent variables included in the analysis. In our analyses, each $1 \%$ equals 1.44 months, or each $8.33 \%$ equals one year.

*AIC (Akaike Information Criterion), a statistic proposed by Akaike (source Akaike $\mathrm{H}, \mathrm{A}$ new look at the statistical model identification, IEEE Transactions on Automatic Control, 1974, 19(6):716-723), is used for judging the best-fitting parametric model. According to Akaike, the best-fitting model is the one with the lowest AIC statistic. 


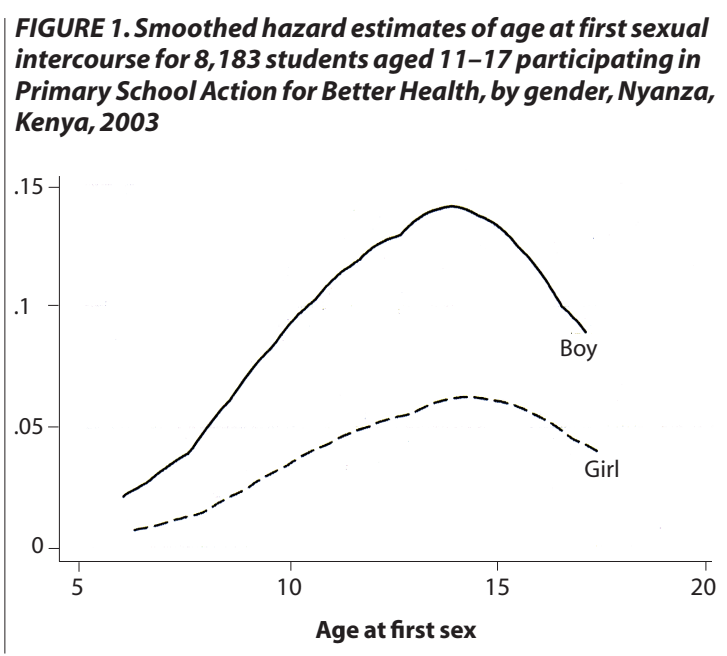

The STATA software used in this analysis dealt with the possibility of biased standard errors resulting from the clustered sampling design by imposing a cluster variable, in this case, the school. In line with Cleves, Gould and Gutierrez's ${ }^{42}$ conclusion that, in most cases, observations are also correlated within groups because of an overall, unmeasured group characteristic, we used the shared frailty* term in our event history models as a way of examining whether heterogeneity exists at the school level.

\section{RESULTS}

All students were never-married (not shown), and ranged from 11 to 17 years old (Table 1). Sixty-two percent of males and $30 \%$ of females had already had sexual intercourse. According to life tables used to correct for right censoring, the median age at first sexual intercourse was 14 for males and 17 for females (not shown). Males had higher mean scores for both prevention knowledge and endorsement of HIV transmission myths than did females. The mean sexual pressure score was also higher among males than females. Despite the high HIV prevalence in this region, ${ }^{37}$ a large proportion of students did not think they were at risk of HIV infection (37\% of males and 55\% of females). However, more males than females thought they were at great risk (23\% and 17\%, respectively). Also, more females than males ( $57 \%$ vs. $52 \%$ ) reported knowing someone who had died of AIDS. Females had a high mean score for abstinence self-efficacy, but a low mean score for condom use self-efficacy, while the opposite was true for males.

The largest proportion of males were Catholics (48\%), while the largest proportion of females were Protestants (51\%). More than half of all respondents identified as Luos (Nyanza is predominantly Luo). On average, males in our

${ }^{*}$ According to Cleves et al., ${ }^{42}$ shared frailty models could be viewed as analogous to random-effects models. The only difference is that we cannot estimate the heterogeneity introduced by community- and schoollevel characteristics, nor can we introduce covariates at the community or school level to explain away the heterogeneity. It is possible, however, to model this heterogeneity in the form of theta, which represents the grouplevel effects. sample were a year older than females ( 15 vs. 14 years).

For respondents who had had sex, first sexual partners were relatively close in age; more than $90 \%$ of participants reported an age difference of two or fewer years. For both males and females, a very high proportion of first partners came from their village; many had met their partner through school, while fewer had met through family members. There was no association between the source and age of first partners (not shown). For a large majority of males (79\%), first sex was wanted (as opposed to forced); almost equal proportions of females reported that it was wanted or forced ( $52 \%$ and $48 \%$, respectively).

\section{Bivariate Results}

For both genders, prevention knowledge, rejection of myths and experiencing fewer pressures to engage in sexual intercourse were associated with lower odds of ever having had sex and delayed timing of first intercourse (Table 2). Abstinence self-efficacy was associated with

\section{TABLE 2. Odds ratios and time ratios from bivariate analyses to identify associations between selected characteristics and ever having had sexual intercourse and age at first sexual intercourse, by gender}

\begin{tabular}{|c|c|c|c|c|c|c|}
\hline \multirow[t]{2}{*}{ Variable } & \multicolumn{3}{|l|}{ Males } & \multicolumn{3}{|c|}{ Females } \\
\hline & $\mathrm{N}$ & $\begin{array}{l}\text { Odds ratio } \\
\text { of ever } \\
\text { having } \\
\text { had sex }\end{array}$ & $\begin{array}{l}\text { Time ratio } \\
\text { for age at } \\
\text { first sex }\end{array}$ & $\mathrm{N}$ & $\begin{array}{l}\text { Odds ratio } \\
\text { of ever } \\
\text { having } \\
\text { had sex }\end{array}$ & $\begin{array}{l}\text { Time ratio } \\
\text { for age at } \\
\text { first sex }\end{array}$ \\
\hline \multicolumn{7}{|l|}{ KNOWLEDGE } \\
\hline $\begin{array}{l}\text { Prevention knowledge } \\
\text { Endorsement of }\end{array}$ & 4,052 & $0.78^{* * *}$ & $1.03^{* * *}$ & 3,990 & $0.82^{* * *}$ & $1.04^{* * *}$ \\
\hline transmission myths & 4,052 & $1.18^{* * *}$ & $0.96^{* * *}$ & 3,990 & $1.31^{* * *}$ & $0.95^{* * *}$ \\
\hline \multicolumn{7}{|l|}{ MOTIVATION } \\
\hline Sexual pressure & 4,146 & $4.70^{* * *}$ & $0.87^{* * *}$ & 4,037 & $4.07^{* * *}$ & $0.81^{* * *}$ \\
\hline \multicolumn{7}{|l|}{ Perceived risk } \\
\hline None (ref) & 1,512 & 1.00 & 1.00 & 2,185 & 1.00 & 1.00 \\
\hline Small & 1,043 & $2.07^{* * *}$ & $0.92^{* * *}$ & 688 & $2.50^{* * *}$ & $0.86^{* * *}$ \\
\hline Moderate & 593 & $1.23^{*}$ & 0.97 & 470 & $2.03^{* * *}$ & $0.89^{* * *}$ \\
\hline Great & 952 & $1.31^{* * *}$ & $0.94^{* * *}$ & 659 & $1.31^{* *}$ & $0.95^{* *}$ \\
\hline \multicolumn{7}{|c|}{ Knew someone who had died of AIDS } \\
\hline No (ref) & 1,866 & 1.00 & 1.00 & 1,615 & 1.00 & 1.00 \\
\hline Yes & 2,147 & $1.50^{* * *}$ & $0.97^{* * *}$ & 2,319 & $1.58^{* * *}$ & $0.94^{* * *}$ \\
\hline Don't know & 133 & $1.72^{* * *}$ & 0.96 & 103 & $2.37^{* * *}$ & $0.91^{* *}$ \\
\hline \multicolumn{7}{|c|}{ BEHAVIORAL SELF-EFFICACY } \\
\hline Abstinence & 3,807 & $0.76^{* * *}$ & $1.01^{* *}$ & 3,643 & 1.02 & 1.00 \\
\hline Condom use & 3,807 & 0.99 & 0.99 & 3,643 & $1.22^{* * *}$ & $0.97^{* * *}$ \\
\hline \multicolumn{7}{|l|}{ DEMOGRAPHIC } \\
\hline \multicolumn{7}{|l|}{ Religion } \\
\hline Catholic (ref) & 1,998 & 1.00 & 1.00 & 1,920 & 1.00 & 1.00 \\
\hline Protestant & 1,883 & 1.02 & 0.99 & 2,070 & 0.88 & 1.01 \\
\hline Other & 265 & 0.94 & 0.99 & 147 & 0.73 & 1.02 \\
\hline \multicolumn{7}{|l|}{ Ethnicity } \\
\hline Luo (ref) & 2,378 & 1.00 & 1.00 & 2,249 & 1.00 & 1.00 \\
\hline Kisii & 1,148 & 1.25 & 1.00 & 1,496 & $0.72^{* *}$ & 1.03 \\
\hline Other & 320 & $0.60^{* *}$ & 1.04 & 292 & $0.35^{* * *}$ & $1.10^{* *}$ \\
\hline Age & 4,146 & $1.19^{* * *}$ & na & 4,037 & $1.26^{* * *}$ & na \\
\hline
\end{tabular}

${ }^{*} \mathrm{p} \leq .05 .{ }^{* *} \mathrm{p} \leq .01 .{ }^{* * *} \mathrm{p} \leq .001$. Notes: Time ratios greater than one mean sex took place later compared with the reference group, and those less than one, that sex took place earlier compared with the reference group. For scalar measures, time ratios greater than one indicate later sexual initiation for respondents scoring higher on the independent variable and those less than one indicate earlier sexual initiation for such respondents. ref=reference group. na=not applicable. 
TABLE 3. Time ratios (and standard errors) from multivariate hazards models of age at first sexual intercourse, by gender Variable Males $(\mathrm{N}=3,701)$

KNOWEDGE

KNOWLEDGE

Prevention knowledge

Endorsement of transmission myths

MOTIVATION

Sexual pressure

Perceived risk

None (ref)

Small

Moderate

Great

Knew someone who had died of AIDS

No (ref)

Yes

Don't know

BEHAVIORAL SELF-EFFICACY

Abstinence

Condom use

Abstinence $\times$ condom use

DEMOGRAPHIC

Religion

Catholic (ref)

Protestant

Other

\section{Ethnicity}

Luo (ref)

Kisii

Other

Shared frailty (theta)

Number of failures

Logpseudolikelihood

Model significance (Wald $\chi^{2}$ )

\begin{tabular}{|c|c|c|c|c|c|}
\hline \multicolumn{3}{|c|}{ Males $(\mathrm{N}=3,701)$} & \multicolumn{3}{|c|}{ Females $(\mathrm{N}=3,584)$} \\
\hline Model 1 & Model 2 & Model 3 & Model 1 & Model 2 & Model 3 \\
\hline $1.01(0.01)$ & $1.01(0.01)$ & $1.01(0.01)$ & $0.99(0.01)$ & $0.99(0.01)$ & $1.00(0.01)$ \\
\hline $0.98(0.01)^{* * * *}$ & $0.98(0.01)^{* * *}$ & $0.98(0.01)^{* * *}$ & $0.97(0.01)^{* * *}$ & $0.97(0.01)^{* * *}$ & $0.97(0.01)^{* * *}$ \\
\hline $0.87(0.01)^{* * *}$ & $0.87(0.01)^{* * *}$ & $0.87(0.01)^{* * *}$ & $0.81(0.01)^{* * *}$ & $0.81(0.01)^{* * *}$ & $0.81(0.01)^{* * *}$ \\
\hline 1.00 & 1.00 & 1.00 & 1.00 & 1.00 & 1.00 \\
\hline $0.95(0.01)^{* * *}$ & $0.95(0.01)^{* * * *}$ & $0.95(0.01)^{* * *}$ & $0.90(0.02)^{* * * *}$ & $0.90(0.02)^{* * *}$ & $0.90(0.02)^{* * * *}$ \\
\hline $0.99(0.02)$ & $0.99(0.02)$ & $0.99(0.02)$ & $0.94(0.02)^{* *}$ & $0.94(0.02)^{* *}$ & $0.94(0.02)^{* * *}$ \\
\hline $0.96(0.01)^{* * * *}$ & $0.96(0.02)^{* *}$ & $0.96(0.02)^{* *}$ & $0.99(0.02)$ & $0.99(0.02)$ & $0.99(0.02)$ \\
\hline 1.00 & 1.00 & 1.00 & 1.00 & 1.00 & 1.00 \\
\hline $0.98(0.01)$ & $0.98(0.01)$ & $0.98(0.01)$ & $0.98(0.02)$ & $0.98(0.02)$ & $0.98(0.02)$ \\
\hline $0.98(0.04)$ & $0.98(0.04)$ & $0.98(0.04)$ & $1.00(0.05)$ & $1.00(0.05)$ & $1.00(0.05)$ \\
\hline $1.01(0.01)^{* *}$ & $1.02(0.01)^{* *}$ & $1.01(0.01)^{* *}$ & $1.00(0.01)$ & $1.01(0.01)$ & $1.01(0.01)$ \\
\hline na & $0.99(0.01)$ & $1.00(0.01)$ & na & $0.98(0.01)^{* *}$ & $0.98(0.01)^{* *}$ \\
\hline na & na & $1.02(0.01)^{* *}$ & na & na & $1.01(0.01)$ \\
\hline na & na & 1.00 & na & na & 1.00 \\
\hline na & na & $0.98(0.01)^{*}$ & na & na & $1.01(0.02)$ \\
\hline na & na & $0.99(0.02)$ & na & na & $1.03(0.05)$ \\
\hline na & na & 1.00 & na & na & 1.00 \\
\hline na & na & $0.98(0.02)$ & na & na & $1.00(0.03)$ \\
\hline na & na & $1.05(0.03)$ & na & na & $1.12(0.05)^{* * *}$ \\
\hline $0.18(0.03)^{* * *}$ & $0.18(0.03)$ & $0.17(0.03)^{* * *}$ & $0.35(0.07)^{* * *}$ & $0.35(0.06)^{* * *}$ & $0.33(0.06)^{* * *}$ \\
\hline 2,269 & 2,269 & 2,269 & 1,083 & 1,083 & 1,083 \\
\hline$-1,413.8$ & $-1,413.3$ & $-1,406.4$ & $-1,260.6$ & $-1,258.6$ & $-1,254.0$ \\
\hline $429.35(9)^{* * *}$ & $430.25(10)^{* * *}$ & $444.00(14)^{* * *}$ & $558.97(9)^{* * *}$ & $562.90(10)^{* * *}$ & $572.20(14)^{* * * *}$ \\
\hline
\end{tabular}

${ }^{*} \mathrm{p} \leq .05 .{ }^{* *} \mathrm{p} \leq .01 .{ }^{* * *} \mathrm{p} \leq .001$. Notes: Standard errors are adjusted for clustered sampling design. Number of failures is the number in each model who have experienced sexual intercourse. ref=reference group. na=not applicable.

lower odds of first sex and with delayed timing for males, but not for females. Contrary to our predictions, greater perceived risk and knowing someone who had died of AIDS were associated with higher odds of having had sex and earlier timing of first sex for both genders. Among females, but not males, higher condom self-efficacy was associated with having engaged in sexual intercourse and earlier timing. Finally, ethnicity was associated with having had sexual intercourse for both males and females and with its timing for females only.

\section{Multivariate Results}

Six multivariate hazard models-three for males and three for females-of timing of first intercourse are presented in Table 3. In the first model, we estimated the effect of the primary independent variables from the IMB model on respondents' timing of first sex. In the second model, we added condom use self-efficacy, and in the third, we added religion, ethnicity and a term for interaction between condom use self-efficacy and abstinence self-efficacy. Table 4 uses the same analytic strategy with logit models to identify factors associated with the odds of having had intercourse; in this table, the third model includes age in addition to the variables used in Table 3. In all the event history models, we controlled for shared frailty.

In the first model in Table 3, when the effects of other IMB indicators were accounted for, males and females who endorsed more transmission myths experienced their sexual debut earlier. However, correct knowledge about prevention did not have a significant effect on the timing of sexual intercourse for either males or females.

The size of the time ratios for sexual pressure shows it to be the most influential variable in the multivariate analyses. However, the indicators theorized as motivating youth to delay sexual activity provided only marginal support for our predictions. Males who perceived that they had a great risk of contracting HIV initiated sex $3.8 \%$, or 5.5 months, ${ }^{*}$ ear-

* Because the time ratios shown in Table 3 are rounded to two decimal places, calculations based on those figures are less precise than those appearing in the text. 


\begin{tabular}{|c|c|c|c|c|c|c|}
\hline \multirow[t]{2}{*}{ Variable } & \multicolumn{3}{|l|}{ Males } & \multicolumn{3}{|l|}{ Females } \\
\hline & Model 1 & Model 2 & Model 3 & Model 1 & Model 2 & Model 3 \\
\hline \multicolumn{7}{|l|}{ KNOWLEDGE } \\
\hline Prevention knowledge & $0.94(0.05)$ & $0.94(0.05)$ & $0.95(0.05)$ & $1.03(0.07)$ & $1.02(0.07)$ & $1.02(0.07)$ \\
\hline Endorsement of transmission myths & $1.25(0.07)^{* * *}$ & $1.24(0.07)^{* * *}$ & $1.26(0.07)^{* * *}$ & $1.29(0.10)^{* * *}$ & $1.26(0.09)^{* * *}$ & $1.25(0.09)^{* * *}$ \\
\hline \multicolumn{7}{|l|}{ MOTIVATION } \\
\hline Sexual pressure & $4.44(0.48)^{* * *}$ & $4.43(0.48)^{* * *}$ & $4.42(0.47)^{* * * *}$ & $3.95(0.33)^{* * *}$ & $3.92(0.33)^{* * * *}$ & $3.72(0.31)^{* * *}$ \\
\hline \multicolumn{7}{|l|}{ Perceived risk } \\
\hline None (ref) & 1.00 & 1.00 & 1.00 & 1.00 & 1.00 & 1.00 \\
\hline Small & $1.77(0.20)^{* * *}$ & $1.77(0.20)^{* * *}$ & $1.75(0.20)^{* * *}$ & $2.11(0.27)^{* * *}$ & $2.09(0.27)^{* * *}$ & $2.04(0.26)^{* * *}$ \\
\hline Moderate & $1.04(0.14)$ & $1.04(0.14)$ & $1.00(0.14)$ & $1.62(0.24)^{* * *}$ & $1.64(0.24)^{* * *}$ & $1.67(0.25)^{* * *}$ \\
\hline Great & $1.21(0.12)^{*}$ & $1.20(0.12)^{*}$ & $1.18(0.13)$ & $1.16(0.19)$ & $1.18(0.20)$ & $1.19(0.20)$ \\
\hline \multicolumn{7}{|l|}{ Knew someone who had died of AIDS } \\
\hline No (ref) & 1.00 & 1.00 & 1.00 & 1.00 & 1.00 & 1.00 \\
\hline Yes & $1.30(0.10)^{* * *}$ & $1.30(0.10)^{* * *}$ & $1.23(0.10)^{* * *}$ & $1.33(0.13)^{* * *}$ & $1.33(0.13)^{* * *}$ & $1.35(0.14)^{* * *}$ \\
\hline Don't know & $1.27(0.32)$ & $1.28(0.32)$ & $1.29(0.32)$ & $1.33(0.35)$ & $1.33(0.35)$ & $1.24(0.33)$ \\
\hline \multicolumn{7}{|l|}{ BEHAVIORAL SELF- EFFICACY } \\
\hline Abstinence & $0.78(0.04)^{* * *}$ & $0.77(0.04)^{* * *}$ & $0.80(0.04)^{* * *}$ & $0.98(0.06)$ & $0.95(0.05)$ & $0.94(0.05)$ \\
\hline Condom use & na & $1.04(0.06)$ & $1.03(0.05)$ & na & $1.13(0.07)^{* *}$ & $1.10(0.07)^{*}$ \\
\hline Abstinence $\times$ condom use & na & na & $0.88(0.04)^{* * *}$ & na & na & $0.99(0.05)$ \\
\hline \multicolumn{7}{|l|}{ DEMOGRAPHIC } \\
\hline \multicolumn{7}{|l|}{ Religion } \\
\hline Catholic (ref) & na & na & 1.00 & na & na & 1.00 \\
\hline Protestant & na & na & $1.15(0.10)$ & na & na & $0.96(0.10)$ \\
\hline Other & na & na & $1.09(0.20)$ & na & na & $0.73(0.24)$ \\
\hline \multicolumn{7}{|l|}{ Ethnicity } \\
\hline Luo (ref) & na & na & 1.00 & na & na & 1.00 \\
\hline Kisii & na & na & $1.41(0.24)^{* *}$ & na & na & $0.82(0.13)$ \\
\hline Other & na & na & $0.59(0.13)^{* *}$ & na & na & $0.38(0.09)^{* * *}$ \\
\hline Age & na & na & $1.14(0.04)^{* * *}$ & na & na & $1.18(0.04)^{* * * *}$ \\
\hline Logpseudolikelihood & $-1,957.4$ & $-1,957.1$ & $-1,926.7$ & $-1,741.5$ & $-1,737.9$ & $-1,706.6$ \\
\hline Model significance (Wald $\chi^{2}$ ) & $280.29(9)^{* * *}$ & $289.61(10)^{* * *}$ & $380.89(16)^{* * *}$ & $317.03(9)^{* * *}$ & $361.36(10)^{* * *}$ & $377.22(16)^{* * *}$ \\
\hline Pseudo $R^{2}$ & .204 & .204 & .217 & .212 & .214 & .228 \\
\hline
\end{tabular}

lier than those who said they had no risk of infection; this finding is counter to predictions. However, males who felt they had only a small chance of becoming infected with HIV initiated sex $5.4 \%$, or 7.8 months, earlier than those who felt they were at no risk. The pattern was similar for females, although the size of the effects was larger, except for those who felt they were at great risk. For both males and females, knowing someone who had died of AIDS did not influence the age at which they first engaged in intercourse. Greater abstinence self-efficacy delayed the timing of sexual debut (by $1.3 \%$ or 1.9 months for each unit increase in abstinence self-efficacy) among males, but not among females.

Even after condom use self-efficacy was added in Model 2 , all other variables remained statistically robust. In the model for females, sexual initiation occurred 1.8\% (2.6 months) earlier for each unit increase in condom self-efficacy.

In Model 3, the sociocultural variables ethnicity and religion and the term for interaction between abstinence self-efficacy and condom use self-efficacy were added. All prior variables remained statistically robust, with little change in the size of the time ratios. We found no difference in the timing of sexual initiation across the different ethnic groups for males, but females from nondominant ethnic groups delayed their sexual debut by $12 \%$, or 1.4 years, compared with Luo females. Protestant males initiated sexual intercourse $2.2 \%$, or 3.2 months, earlier than Catholic males. Finally, the interaction of condom use self-efficacy and abstinence selfefficacy demonstrated that, for males, high self-efficacy on both was associated with delayed timing of sexual initiation. There was no significant effect for females.

Theta, the term for shared frailty in the hazard models, was significant in all models except Model 2 for males. Its size decreased in Model 3 with the addition of sociocultural variables. The results for shared frailty suggest that unobserved school-and community-level factors influence the timing of first intercourse.

Results for the logit models (Table 4) are similar to those for the hazard models. In Model 1, once other IMB indicators were considered, as more myths were endorsed, the odds for both males and females of having had intercourse increased (odds ratio, 1.3 for each). 
The size of the adjusted odds ratios for sexual pressure shows this to be the most influential variable (odds ratio, 4.4 for males and 4.0 for females). However, the indicators theorized as motivating youth to delay sexual activity provided only marginal support for our predictions. Compared with males who felt they had no risk of contracting HIV, those who perceived that they had a great chance of contracting HIV/AIDS had greater odds of having engaged in sexual intercourse (1.2); the odds for males who felt they had only a small chance of becoming infected with HIV were even higher (1.8). The pattern was similar for females, with higher levels of perceived risk producing lower odds than lower levels of perceived risk, although the size of the odds are greater and the upper threshold of risk that achieved significance is lower for females. Males and females who reported knowing someone who had died of AIDS had higher odds of being sexually experienced than did those who did not know anyone who had died of AIDS (1.3 for each gender).

Greater abstinence self-efficacy reduced the odds of having engaged in sexual intercourse among males (odds ratio, 0.8), but not among females. Even after controlling for condom use self-efficacy in Model 2, all other variables remained statistically robust. In the model for females, the odds of being sexually experienced increased by 1.1 for each unit increase in condom self-efficacy.

All prior variables remained statistically robust with little change in the size of their adjusted odds ratios when sociocultural variables and the interaction between condom use self-efficacy and abstinence self-efficacy were added in Model 3. The one exception was great perceived risk among males, which was no longer significant. Compared with their Luo counterparts, Kisii males had higher odds of being sexually experienced (odds ratio, 1.4), and both males and females from other ethnic groups had lower odds ( 0.6 for males and 0.4 for females). As would be expected, the odds of engaging in sex increased with ageeach one-year increase in age raised the odds of having engaged in sexual intercourse by 1.1 for males and 1.2 for females. Finally, the significant interaction of condom use self-efficacy and abstinence self-efficacy demonstrated that high self-efficacy on both, for males only, was associated with lower odds of sexual experience (0.9).

\section{DISCUSSION}

Results from this study support the conclusion that the ability to reject common local myths about transmission and prevention, experiencing fewer pressures to engage in sex, and abstinence self-efficacy (the latter only for males) are associated with reduced odds of having experienced sexual intercourse and a delay in the timing of first sex. This suggests that these components of the Primary School Action for Better Health program are effective in helping upper primary school pupils delay sexual initiation. The implications of risk perception and awareness of AIDS deaths on the timing of first sexual intercourse are, however, less clear.
Awareness of HIV and knowledge about its transmission through sexual activity are high throughout most of Sub-Saharan Africa. ${ }^{2,43}$ It is therefore not surprising that the influence of prevention knowledge on delaying sexual intercourse seen in the bivariate analysis was not retained in the multivariate analysis; only rejection of transmission myths maintained an effect. These results suggest that prevention knowledge may work through or in concert with other predictors, whereas endorsement or rejection of transmission myths operates independently of the other covariates considered here. The program implication of this finding is that it is not enough to convey "the facts" about HIV transmission and prevention, it is also important to understand and counter local myths.

Consistent with the IMB model, a perception of being at risk was conceptualized as a motivation to delay sexual intercourse. Contrary to this expectation, we found that youth who felt they had any risk of contracting HIV were more likely to be sexually experienced and to have initiated sex earlier than those who felt they had no risk. Although this finding is the opposite of what is predicted by the IMB and similar models, it is consistent with results of some previous studies. $1,27,43,44$ These counterintuitive results may reflect an issue of timing and the interdependence of risk perception and sexual behavior. As theorized, the level of perceived risk that precedes sexual behavior influences that behavior. However, once sexual behavior has occurred, the level of perceived risk may be modified to reflect that behavior. This type of interdependence can only be fully examined with longitudinal data, as demonstrated by Anderson and colleagues ${ }^{26}$ and Tenkorang and Fernando. ${ }^{28}$ In cross-sectional samples such as ours, and those found in most other studies, it is not possible to determine whether the level of perceived risk that is measured preceded or followed the sexual behavior. We note that in the current study, when students who felt they were at no risk of contracting HIV were removed from consideration, the expected pattern of effects appeared across the different degrees of perceived risk. This suggests that there may be an optimal level of risk perception for reducing risk-taking

Alternatively, the source of risk may be important. Some youth may have felt at risk as a result of circumstances that have no relationship to sexual activity (e.g., male or female circumcision with common instruments, shared sharps, medical treatments, witchcraft and casual contact with others). Clearly the relationship between risk perception and action is more complex than is often acknowledged. Given that the first focus of prevention campaigns is often on motivating people to protect themselves by raising their awareness that they are at risk, more research is needed to understand how risk perception influences behaviors and longitudinal data are needed to examine how risk perception and sexual behavior influence each other.

Results from the analysis also indicate that knowing someone who had died of AIDS was associated with being sexually experienced and with earlier initiation of first sex. 
Several reasons may account for these counterintuitive results. First, as with risk perception, the cross-sectional nature of our data does not allow us to disentangle the causal order. The death may well have occurred after sexual debut and the association may be spurious or perhaps indicative of a higher awareness of community members who are dying of AIDS once one is sexually active. Or perhaps, as Macintyre et al. ${ }^{27}$ have argued, the impact of knowing someone who has died of AIDS on sexual risk behavior may be contingent on the relationship between the deceased and the respondent. Change may occur only if the death is of someone close to the respondent, such as a relative or someone from one's peer group. Alternatively, knowing someone who has died of AIDS may contribute to a sense of fatalism, i.e., "I'm going to die anyway." Studies in South Africa and Malawi have demonstrated that fatalism inhibits preventive behaviors. ${ }^{45,46}$ As AIDS deaths become increasingly visible in many countries of SubSaharan Africa, more careful attention needs to be paid to understanding how the experience of these deaths influences motivation to protect oneself.

Multiple studies in Sub-Saharan Africa suggest that youth have sex for the first time because of social pressures and environmental conditions. 6,16,28,47,48 Pressure on females comes from their subordinate position to males and cultural scripts that make access to material resources through sexual activity normative for females. ${ }^{6,13,16} \mathrm{Re}$ search by Varga ${ }^{49}$ among males in South Africa and by Nzioka ${ }^{20,21}$ in Kenya shows that males are pressured to be highly sexually active in order to be socially recognized as physically mature or appropriately masculine. In the current study, sexual pressure was the factor with the strongest effect on both measures of sexual initiation. When considered together with the results for abstinence self-efficacy, a gendered picture of the experience of sexual initiation is evident. Considerably more males than females reported they were sexually experienced and that they had initiated sexual intercourse earlier in their teenage years (mean age of 14 vs. 17). The majority of males reported that their first sexual experience was wanted rather than forced; however, they also experienced higher levels of pressure to engage in sexual activity and had lower abstinence self-efficacy than females did. The influence of pressure on the odds of having experienced sexual intercourse was stronger for males, whereas its influence on earlier timing of sexual initiation was stronger for females. Males with higher abstinence self-efficacy delayed initiation and had lower odds of being sexually experienced. Despite their higher levels of abstinence self-efficacy, females were not able to postpone sexual initiation, which may reflect the high percentage of females who reported that their first intercourse was forced rather than wanted.

The programmatic implication of these results is that instructing youth to "just say no" is insufficient. Young people need to learn how to counter the pressures they are experiencing, and females, in particular, need to have a way to gain control of the sexual circumstances of their lives.
The Primary School Action for Better Health program addressed the pressures that youth reported facing by attempting to debunk those that were based on myth (e.g., when you feel desire, it is essential to engage in sexual intercourse or you will suffer ill health) and to teach ways to avoid or challenge others (e.g., avoiding places and circumstances where sexual activity and especially coercion is common, staying in same-sex groups, challenging peers who pressure you to engage in sex).

However, the very strong effect shown in our analyses of sexual pressure on debut even when other predictors were taken into account suggests that what is being taught is not enough. To reduce the effects of pressure quite likely requires community and societal changes and policy initiatives. Many of the pressures identified by youths emanated from community norms, the actions of older adults, and financial needs and incentives, all of which are beyond their individual control and must be addressed through local and national policies and programs targeting social conditions.

Currently, there is considerable debate as to whether the emphasis in AIDS prevention campaigns should be on abstinence and delaying sexual activity or on condom use. Green ${ }^{50}$ has argued that a focus on condom use has been imported to Africa from Western prevention campaigns that do not address the situation in Sub-Saharan Africa. Efforts to teach about condoms in Africa can provoke strong negative reactions. Several school-based HIV prevention programs that included condoms were either forced to remove the condom content or withdrawn from the school. ${ }^{51}$ Concerns that knowledge about condoms would contribute to earlier sexual initiation are not supported in the results for males; indeed, high levels of both abstinence self-efficacy and condom use self-efficacy were associated with lower odds of being sexually experienced and a delay in sexual initiation. Although higher condom self-efficacy was associated with higher odds of sexual experience and earlier timing of initiation among females, the cross-sectional nature of our data do not allow us to discern the causal order between sexual activity and condom use self-efficacy. It is quite plausible that having experience with sexual activity leads females to learn how to use condoms to protect themselves. Even if condom selfefficacy precedes sexual activity, this must be considered in light of the high proportions of females who report their first intercourse is a result of force or who delay first intercourse to the late teenage years. Clearly, there is a need for more research addressing the skills youth require in the context of sexuality in their communities.

The introduction of ethnicity and religion did not weaken the effects of the other variables in the model. However, the significance of the shared frailty term demonstrates that social, cultural and environmental conditions are additional forces or influences that need to be considered in developing programs and policies to combat the spread of HIV. These are beyond the domain of individually focused programming, and will require policy and pro-

\section{The}

programmatic

implication of

these results is

that instructing

youth to

"just say no"

is insufficient. 
grams designed to counteract and shift conditions that make youth vulnerable to HIV infection.

\section{Study Limitations}

Several limitations to the generalizability of the results of this study must be considered. Recognizing the concerns that have been raised about the reliability of self-reported data, especially when they deal with sensitive issues like sexual behavior, ${ }^{52-55}$ we used several procedures in preparation for and in conducting data collection to achieve the highest possible validity. First, questions and survey format came from previously tested instruments, ${ }^{41}$ combined with locally appropriate terminology and context obtained as part of elicitation research. Second, questionnaires were piloted with statistical testing of reliability, internal and construct validity of questions, and qualitative feedback from youth was used to further refine the data collection instruments and procedures. Third, combined self-report and structured interviewing were used to minimize interviewer effect ${ }^{54,56}$ and compensate for limited literacy. The only method that might have produced more valid survey results is computer-assisted survey administration (CASI or ACASI), ${ }^{54,56}$ which was not feasible for this study because of cost and the incompatibility of the technology with the local conditions (e.g., absence of electricity, unfamiliarity with and suspicion of computer technology). In addition, we conducted separate analyses, using different statistical approaches, on two measures of sexual experience, using the recommended analysis procedure ${ }^{52}$ (survival analysis) for censored data. The similarity of the patterns of effects on the two dependent variables increases our confidence in our results and suggests that respondents were consistent in reporting sexual activity across different questions. Cleland et al. ${ }^{55}$ note, in their introduction to a special issue of Sexually Transmitted Infections on research design, that carefully collected self-reported data continue to provide essential insights in research on sexuality, despite their shortcomings. We must, however, continue to acknowledge the difficulties involved in using self-reported data when conducting analyses related to sexual activity.

The use of cross-sectional data also limited the interpretation of our results. Although we can make inferences about associations between independent and dependent variables, we cannot draw causal inferences. Use of longitudinal data would have been preferable, but collection of such information was not considered feasible because of high rates of mobility for families and youth that were exacerbated, in part, by high levels of HIV and AIDS, local poverty and the family disruptions these factors caused. In addition, when free primary education was introduced in January 2003, families shifted their children to more desirable schools. Because of the problems these circumstances caused for longitudinal follow-up and because our aim for the Primary School Action for Better Health program was that it demonstrate effectiveness with succeeding cohorts of students, we chose to conduct repeated cross-sectional sampling, recognizing the limitations this imposed on our interpretations.

A final limitation is that the research reported here uses data from only one province in Kenya. By December 2007, the Primary School Action for Better Health program was running in all elementary schools in Kenya and monitoring results indicated that the implications for all the variables included in the analyses presented in this article were similar. However, the specific analyses conducted here would need to be replicated before the results could be generalized beyond Nyanza Province.

\section{CONCLUSION}

As part of the fight against the AIDS pandemic in Kenya, President Mwai Kibaki declared a "total war on AIDS," which has involved a multisectoral response to the disease and made youth the target of AIDS prevention efforts. This has led Kenya to initiate HIV prevention education at all levels of schooling. The focus on delaying first sexual intercourse is central to this initiative. The results reported here shed light on some of the factors associated with the timing of first sexual intercourse that may readily be addressed in school-based prevention programming. The results also highlight the limitations in what can be accomplished through school programming. From these results, we conclude that important components of HIV prevention initiatives include debunking enduring myths and misconceptions about AIDS transmission and prevention, reducing the social pressures exerted on youth to become sexually active at a young age, counteracting the potential sense of fatalism that youth may be experiencing related to HIV and AIDS, addressing the gendered nature of pressure and force, and redressing the imbalance in power between females and males in the sexual arena. Programs must also take account of ethnic differences in how sexuality, sexual behaviors and HIV/AIDS are viewed and the gender differentials in the ability of youth to change their sexual behaviors.

\section{REFERENCES}

1. Akwara PA, Madise NJ and Hinde A, Perception of risk of HIV/AIDS and sexual behaviour in Kenya, Journal of Biosocial Science, 2003, 35(3):385-411.

2. Desgrées du Loû A, Reproductive health and AIDS in Sub-Saharan Africa: problems and prospects, Population: An English Selection, 1999, Vol. 11, pp. 61-87.

3. Tapert SF et al., Adolescent substance use and sexual risk-taking behavior, Journal of Adolescent Health, 2001, 28(3):181-189.

4. Bongaarts J, Late marriage and the HIV epidemic in Sub-Saharan Africa, Population Studies, 2007, 61(1):73-83

5. Owuamanam DO, Sexual networking among youth in southwestern Nigeria, Health Transition Review, 1995, 5(Suppl.):57-66.

6. Zulu EM, Dodoo FN and Ezeh AC, Sexual risk-taking in the slums of Nairobi, Kenya, 1993-8, Population Studies, 2002, 56(3):311-323.

7. Lugoe WL and Biswalo PM, Self-restraining and condom use behaviours: the HIV/AIDS prevention challenges in Tanzanian schools, International Journal of Adolescence and Youth, 1997, 7:67-81.

8. Hulton LA, Cullen R and Khalokho SW, Perceptions of the risks of sexual activity and their consequences among Ugandan adolescents, 
Studies in Family Planning, 2000, 31(1):35-46.

9. Harrison A, Xaba N and Kunene P, Understanding safe sex: gender narratives of HIV and pregnancy prevention among rural South African school-going adolescents, Reproductive Health Matters, 2001, 9(17):63-71.

10. Ajuwon AJ et al., HIV risk-related behavior, sexual coercion, and implications for prevention strategies among female apprentice tailors, Ibadan, Nigeria, AIDS and Behavior, 2002, 6(3):229-235.

11. Jejeebhoy SJ and Bott S, Non-consensual sexual experiences of young people: a review of the evidence from developing countries, Population Council Working Paper, New Delhi: Population Council, 2003, No. 16.

12. Longfield $\mathrm{K}$ and Klein M, Giving in to sexual demand: sexual decision-making among youth, paper presented at the annual meeting of the American Public Health Association, San Francisco, CA, USA, Nov. 15-19, 2003

13. Mensch BS, Bruce J and Greene ME, The Uncharted Passage: Girls' Adolescence in the Developing World, New York: Population Council, 1998.

14. Caldwell JC and Caldwell P, Toward an epidemiological model of AIDS in Sub-Saharan Africa, Social Science History, 1996, 20(4):559591.

15. Luke N, Age and economic asymmetries in the sexual relationships of adolescent girls in Sub-Saharan Africa, Studies in Family Planning, 2003, 34(2):67-86.

16. Maticka-Tyndale E et al., The sexual scripts of Kenyan young people and HIV prevention, Culture, Health and Sexuality, 2005, 7(1):2741

17. Maticka-Tyndale E et al., Primary School Action for Better Health: Preprogramme Integrated Qualitative and Quantitative Report, 2002, <http://web2.uwindsor.ca/courses/sociology/maticka/psabh/evaluation _of_PSABH/pre-programme/wavelreport.pdf>, accessed Dec. 11, 2008.

18. Okonofua F, Adolescent reproductive health in Africa: future challenges, African Journal of Reproductive Health, 2000, 4(1):7-12

19. Orubuloye IO et al., Sexual networking and AIDS in Sub-Saharan Africa: behavioural research and the social context, in: Caldwell J, Caldwell P and Quiggin P, eds., The Social Context of AIDS in SubSaharan Africa, Canberra, Australia: Australian National University, 1994, pp. 129-161.

20. Nzioka C, Lay perceptions of HIV infection and the social construction of safer sex: some experiences from Kenya, AIDS Care, 1996, $8(5): 565-579$

21. Nzioka C, Perspectives of adolescent boys on the risks of unwanted pregnancy and sexually transmitted infections: Kenya, Reproductive Health Matters, 2001, 9(17):108-117.

22. Rosenstock IM, The Health Belief model and preventive health behavior, Health Education Monographs, 1974, Vol. 2, No. 4, pp. 354-386.

23. Ajzen I and Fishbein M, Understanding Attitudes and Predicting Social Behavior, Englewood Cliffs, NJ, USA: Prentice Hall, 1980.

24. Bandura A, Social cognitive theory and exercise of control over HIV infection, in: DiClemente RJ and Peterson JL, eds., Preventing AIDS: Theories and Methods of Behavioral Interventions, New York: Plenum, 1994 , pp. $25-59$

25. Catania JA, Kegeles SM and Coates TJ, Towards an understanding of risk behavior: an AIDS Risk Reduction Model (ARRM), Health Education Quarterly, 1990, 17(1):53-72.

26. Anderson KG, Beutel AM and Maughan-Brown B, HIV risk perceptions and first sexual intercourse among youth in Cape Town, South Africa, International Family Planning Perspectives, 2007, 33(3): 98-105.

27. Macintyre K et al., Understanding perceptions of HIV risk among adolescents in KwaZulu-Natal, AIDS and Behavior, 2004, 8(3):237250
28. Tenkorang EY and Fernando R, Perceived risks of HIV/AIDS and first sexual intercourse among youth in Cape Town, South Africa paper presented at the International Seminar on Potential and Actual Contributions of Behavioural Change to Curbing the Spread of HIV International Union for Scientific Study of Population and Population Council, Entebbe, Uganda, Feb. 18-20, 2008.

29. Fisher JD and Fisher WA, Changing AIDS-risk behavior, Psychological Bulletin, 1992, 111(3):455-474

30. Fisher JD and Fisher WA, Theoretical approaches to individuallevel change in HIV-risk behavior, in: Peterson JL and DiClemente RJ, eds., HIV Prevention Handbook, New York: Kluwer Academic/Plenum, 2000, pp. 3-55.

31. Fisher WA and Fisher JD, A general social psychological model for changing AIDS risk behavior, in: Pryor J and Reeder G, eds., The Social Psychology of HIV Infection, Hillsdale, NJ, USA: Erlbaum, 1993, pp. 127-153.

32. Fisher WA et al., Understanding AIDS risk behavior among sexually active urban adolescents: an empirical test of the InformationMotivation-Behavioral Skills model, AIDS and Behavior, 1999, 3(1):1323.

33. Fisher JD et al., Changing AIDS risk behavior: effects of an intervention emphasizing AIDS risk reduction information, motivation, and behavioral skills in a college student population, Health Psychology, 1996, 15(2):114-123.

34. Carey MP et al., Enhancing motivation to reduce the risk of HIV infection for economically disadvantaged urban women, Journal of Consulting and Clinical Psychology, 1997, 65(4):531-541.

35. Maticka-Tyndale E, Wildish J and Gichuru M, HIV/AIDS and education: experience in changing behaviour: a Kenyan example, Commonwealth Education Partnerships 2004, London: Stationery Office (Great Britain), 2004, pp. 172-175.

36. Buvé A et al., The multicentre study on factors determining the differential spread of HIV in four African cities: summary and conclusions, AIDS, 2001, 15(Suppl. 4):S127-S131.

37. Kenya Ministry of Health, AIDS in Kenya: Background, Projections, Impact, Interventions and Policy, sixth ed., Nairobi, Kenya: Ministry of Health and National AIDS and STD Control Programme, 2001.

38. Kiragu K, Youth and HIV/AIDS: can we avoid a catastrophe? Population Reports, 2001, Series L, No. 12.

39. Maticka-Tyndale E, Wildish J and Gichuru M, Quasi-experimental evaluation of a national primary school HIV intervention in Kenya, Evaluation and Program Planning, 2007, 30(2):172-186.

40. Maticka-Tyndale E, Dilemmas for obtaining consent when work ing with children in high AIDS prevalence regions, National Council on Ethics in Human Research: Case Vignettes, Ottawa, ON, Canada: National Council on Ethics in Human Research, 2004, pp. 7-8

41. WHO, HIV/AIDS Prevention Monitoring and Evaluation Toolkit, Geneva: WHO, 1999.

42. Cleves MA, Gould WW and Gutierrez RG, An Introduction to Survival Analysis Using STATA, revised ed., College Station, TX, USA: Stata, 2004.

43. Bertrand JT et al., AIDS-related knowledge, sexual behavior, and condom use among men and women in Kinshasa, Zaire, in: Bethel ER, ed., AIDS: Readings on a Global Crisis, Boston, MA, USA: Allyn \& Bacon, 1995, pp. 198-298.

44. Cleland J, Risk perception and behavioural change, in: Cleland J and Ferry B, eds., Sexual Behavioural Change and AIDS in the Developing World, London: Taylor and Francis, 1995, pp. 157-192.

45. Forster PG, AIDS in Malawi: contemporary discourse and cultural continuities, African Studies, 2001, 60(2):245-261.

46. Meyer-Weitz A, Understanding fatalism in HIV/AIDS protection: the individual in dialogue with contextual factors, African Journal of AIDS Research, 2005, 4(2):75-82.

47. Ilika A and Igwegbe A, Unintended pregnancy among unmarried adolescents and young women in Anambra State, south east Nigeria, African Journal of Reproductive Health, 2004, 8(3):92-102. 
48. Temin MJ et al., Perceptions of sexual behavior and knowledge about sexually transmitted diseases among adolescents in Benin City, Nigeria, International Family Planning Perspectives, 1999, 25(4):186$190 \& 195$

49. Varga CA, How gender roles influence sexual and reproductive health among South African adolescents, Studies in Family Planning, 2003, 34(3):160-172.

50. Green EC, Rethinking AIDS Prevention: Learning from Successes in Developing Countries, Westport, CT, USA: Praeger, 2003.

51. Gallant M and Maticka-Tyndale E, School-based HIV prevention programmes for African youth, Social Science \& Medicine, 2004, 58(7): 1337-1351.

52. Zaba B et al., Age at first sex: understanding recent trends in African demographic surveys, Sexually Transmitted Infections, 2004, 80(Suppl. II):ii28-ii35

53. Plummer ML et al., "A bit more truthful": the validity of adolescent sexual behaviour data collected in rural northern Tanzania using five methods, Sexually Transmitted Infections, 2004, 80(Suppl. II):ii49-ii56.

54. Hewett PC, Mensch BS and Erulkar AS, Consistency in the reporting of sexual behaviour by adolescent girls in Kenya: a comparison of interviewing methods, Sexually Transmitted Infections, 2004, 80(Suppl. II):ii43-ii48

55. Cleland J et al., Monitoring sexual behaviour in general populations: a synthesis of lessons of the past decade, Sexually Transmitted Infections, 2004, 80(Suppl. II):iil-ii7.

56. Mensch BS, Hewett PC and Erulkar AS, The reporting of sensitive behavior by adolescents: a methodological experiment in Kenya, Demography, 2003, 40(2):247-268.

\section{RESUMEN}

Contexto: A pesar de la relevancia para el riesgo de infección por VIH que tiene el momento en que ocurre la primera relación sexual, pocos estudios han examinado el efecto de posponer la primera relación sexual como una estrategia para evitar la infección.

Métodos: Datos recolectados a partir de una encuesta aplicada en octubre de 2003 a 8,183 estudiantes de sexto y séptimo grados, en edades de 11 a 17 años en 160 escuelas de la Provincia de Nyanza, Kenia, fueron utilizados en modelos de riesgo logit y log-normal para comprender los factores que influyen en el momento de la primera relación sexual.

Resultados: Tanto los hombres como las mujeres que rechazaron los mitos sobre la transmisión del VIH, aquellos que experimentaron menos presión sexual y quienes no conocían a alguien que hubiera muerto de SIDA, así como los hombres que tenían una gran confianza en su capacidad de abstenerse, tuvieron mayor probabilidad de posponer la primera relación sexual que la gente joven que carecía de esas características. Aunque los niveles más bajos de percepción de riesgo de contraer VIH se asociaron con la iniciación sexual temprana, las y los adolescentes que consideraron no estar en riesgo de infección del VIH tuvieron mayor probabilidad de posponer la iniciación sexual. El patrón de asociaciones respecto al género sugiere que los hombres se ven presionados a tener una muy temprana actividad sexual para probar su madurez, aunque los hombres que tuvieron confianza en que podrían abstener- se, así lo hicieron. Las mujeres, sin embargo, no pudieron traducir en abstención esa confianza en la capacidad de abstenerse, y se vieron influenciadas por presiones sociales y del entorno para entablar relaciones sexuales.

Conclusiones: Para apoyar el retraso de la iniciación sexual, la atención de los programas y políticas de prevención del VIH debe concentrarse en disipar los mitos sobre la transmisión del VIH y contrarrestar las presiones que jóvenes de ambos géneros sienten para iniciar la actividad sexual durante su adolescencia temprana.

\section{RÉSUMÉ}

Contexte: Malgré la pertinence du moment des premiers rapports sexuels en ce qui concerne le risque de contraction du $V I H$, peu d'études ont examiné les premiers rapports sexuels différés en tant que stratégie de prévention de l'infection.

Méthodes: Les données d'enquête recueillies en octobre 2003 auprès de 8183 élèves de niveaux 6 et 7 âgés de 11 à 17 ans dans 160 écoles de la province de Nyanza (Kenya), ontété utilisées dans des modèles de risque logit et log-normaux en vue de cerner les facteurs d'influence du moment des premiers rapports sexuels.

Résultats: Tant les jeunes hommes que les jeunes femmes qui rejetaient les mythes relatifs à la transmission du VIH, qui avaient subi moins de pressions de nature sexuelle et qui ne connaissaient pas de victimes du sida, de même que les jeunes hommes plus sûrs de leur aptitude à s'abstenir, se sont avérés plus susceptibles de différer leurs rapports sexuels que les jeunes non associés à ces caractéristiques. Bien que de moindres niveaux de risque perçu de contraction du VIH soient associés à une initiation sexuelle précoce, les adolescents qui estimaient ne pas courir de risque d'infection étaient les plus susceptibles de différer cette initiation. La tendance des associations sexospécifiques laisse entendre que les garçons subissent la pression d'une activité sexuelle très précoce pour prouver leur maturité, bien que ceux confiants en leur capacité de s'abstenir étaient plus susceptibles de résister à cette pression. Côté féminin, toutefois, les filles ne sont pas aptes à concrétiser leur croyance en leur capacité d'abstinence et subissent davantage les pressions sociales et du milieu.

Conclusion: Pour aider à différer l'initiation sexuelle, l'attention des programmes et politiques de prévention du VIH doit se concentrer sur la dissipation des mythes relatifs à la transmission du virus et sur la résistance aux pressions sexospécifiques qui poussent les jeunes à devenir sexuellement actifs dès les premières années de l'adolescence.

\section{Acknowledgments}

The research was funded by the Department for International Development (DFID), UK. The conclusions presented in this article are those of the authors alone and not necessarily those of DFID.

Author contact:maticka@uwindsor.ca 